\title{
Global Curricular Legacies and Challenges FOR THE TwENTY-First CENTURY
}

\author{
Colin Brock ${ }^{\mathrm{a}}$ \\ University of Oxford
}

\begin{abstract}
The intention of this paper is to examine the evolution of what has become a near global and conventional school curriculum, the forces behind its development and the purposes of education, its sponsors and controllers espouse, and to set it against the massive and urgent challenges of the $21^{\text {st }}$ century. This century looks to be a unique one in that it could be the tipping point between human and environmental survival, and disaster on a massive scale. The argument is that this near global view of the purpose of education is misconceived and dangerous unless there is rapid and fundamental change in the purposes of educating the young. Those older than10 are mostly already 'lost'. In search of a more appropriate purpose and structure of curriculum, the work of a prominent few who are not yet 'lost' is drawn upon, especially that of George Martin, founder of the Oxford Martin School. The purpose of education must now, and urgently, be the survival of the human species and the planet, not only in basic terms but also in terms of controlling increasingly powerful and sophisticated computer technologies known as the Singularity that could spiral out of control.
\end{abstract}

KEYWORDS: legacy, curriculum, 21st century, survival, future

\section{What is Curriculum?}

It is self-evident that education systems are extremely comparable as between the 200 or so that exist across the globe. This can be explained by their evolution; a process of cultural imperialism that has long been recognised and documented (Carnoy, 1974). This in turn is due to the fact that formal education has long been controlled and delivered by political forces, namely governments and religious organisations (Brock, 2007). Indeed, these two forces have often operated in tandem, especially with regard to schooling and colonialism. This discussion will not, however, be confined to schooling, partly because conventional curricula have derived from the influence of universities, and also because of the likely greater influence of non-formal and informal modes of education.

This brings us to the crucial issue of the definition of 'curriculum' for the purposes of this discussion. It hinges naturally not only on the view of the writer, but also the spatial and temporal parameters of the title, namely 'global' and 'twenty-first century' respectively; that is to say the changing context over time.

It is customary when seeking definitions to defer to the words of that much respected dictionary of the English language the Oxford English Dictionary. This states that 'curriculum' is: 1. 'the subjects in a course of study', or 2. 'any programme of activities'. Despite its august parentage, there is, curiously, a problem with this definition when applied to education. With respect to the word 'education' the same dictionary gives three definitions: 1 . 'systematic instruction', 2. A particular kind of or stage in education', and 3. 'development of character or mental powers'. It is instructional also to consider the same dictionary's definition of the word 'educated': 1.' having had an education, especially to a higher level than average', or 2. 'resulting from a 'good' education', or 3. 'based on experience or study'.

In view of the significance of the aforementioned changing context over time, the third option of each of these latter two definitions becomes increasingly realistic. That is to say: 'the development of character and mental powers', and 'based on experience or study'. The inclusion in the second definition of the word 'activities' is also preferred by the writer, for as by Belth (1965) states:

Correspondence can be directed to: mvj39k@gmail.com 
In addition to the innumerable unconscious absorptions which occur, whatever modes of thinking the student may use are made available to him by the curriculum which is woven about him in the activities of education' ( p.261).

My preferences are based on what is increasingly happening in the respective influences of the three modes of education (Brock, 2011). That is to say, the on-going day by day relationship between formal, non-formal and informal modes of learning. For most of recorded history all three have been operative, but with the formal mode increasingly dominating as political control increased. Such control was, inter alia, territorial. Bodies of organised religion, and in particular the Christian variants, established political geographical parameters such as parishes and diocese(s). Emerging nations established and contested territories, so that, as in the case of Europe, as Dodgeshon puts it: 'leaders ruled over people through their rule over territory, not over territory through their rule over people' (1987, p.137).

Europe as a scale of reference is important because of the interplay between religious and political on medieval and renaissance schools and universities (Brock, 2010), and the rapid and widespread expansion of the 'European idea of education' (Mallinson, 1980) on an almost global scale (Taylor \& Flint, 2000).

The nature and content of early European schooling was laid down by the universities, themselves under the control of the Christian churches, trading cities and emergent states. The formal curricula of both universities and schools were the product of a combination of Graeco -Roman culture and Christianity. Both exhibited urban and male-oriented elitism to the virtual exclusion of majority rural populations, and females in general. It is only in the last $\mathbf{1 5 0}$ years or so that schooling has become gradually and differentially available to girls and women. Indeed, in the less economically developed regions of the world the continued widespread dominance of patriarchal kinship systems still works to the disadvantage of female participation in education (Brock \& Cammish, 1997). It is in medieval and renaissance Europe that the roots of the majority of school curricula in the world lie, namely conservative, discriminatory and, in general, selective in purpose and function (Hopper, 1968). Early courses of study comprised mainly the classical languages and philosophy, mathematics, history, theology and music. Towards the end of this period European colonisation was broadening through the so-called 'age of discovery'. But with the exception of the use of the vernacular, pioneered by the Lutheran reformation (Dickens, 1984), and the emergence of geography (Elliot \& Daniels, 2010) there was little change in what comprised a 'proper curriculum' for a minority of selected boys. Even the technological advances associated with the agricultural and industrial revolutions of the seventeenth and eighteenth centuries took a very long time for 'science' to be accepted as a normal component of that curriculum. Likewise modern European languages as illustrated by the Leeds Grammar School case of 1806 in England. Leeds emerged as a prosperous city of the industrial age and its merchants wanted to employ the products of its leading school in trading in mainland Europe. They were thwarted by an edict of the Lord Chancellor in London to the effect that the curriculum of Leeds Grammar School should remain a classical one with the pursuit of intellectual excellence as its sole objective (Lawson \& Silver, 1973). Only in the formative decades of the USA, with its decentralised system safeguarded by the Constitution from the clutches of a national elite, was there a radical approach with the emergence of the community-based open school movement in Boston. But this non-elitist model did not begin to influence European education until a century later assisted by the upheavals associated with the World War of 1914-18 and the Bolshevik Revolution of 1917.

Yet within the curriculum of the elitist schools science had begun to take its place during the nineteenth century, and some of these schools were now for girls. Three of the four natural sciences became part of the experience of this selected minority, biology, chemistry and physics, but not except in very rare cases, geology. This significant omission, still obtaining nearly everywhere, will be a key feature of our twenty-first century discussions later. 
So, as universal primary and secondary education came of age in the twentieth century, the firmly embedded and conventional view of the curriculum as a course of study had taken root. But it is not the writer's view either of what it actually is, or should be, in the interests of the purposes of education in the twenty-first century with its unprecedented challenges. Rather it is the result of a convenient conventional wisdom of those controlling and delivering formal education almost everywhere: a collection of subjects.

\section{What are Subjects?}

'.........it is impossible to teach a given body of knowledge as a series of ultimately true assertions. Quite the reverse. Whatever knowledge and beliefs prevail in the society about us should serve as the materials to be shaped into the subject matter for any curriculum. This does not mean that they are already organised to serve that function' (Belth, 1965, p.277).

Belth, an American educator, made this prescient observation nearly half a century ago. It challenges the kind of school curriculum that has emerged over hundreds of years, always behind the times and dysfunctional in terms of the challenges of those times. He doesn't mention subjects as such but talks of shaping the subject matter comprising a curriculum in relation to the knowledge and beliefs in the society around us. Yet what we have in the world today are many societies, many times more than the number of nations and territories. The answer to the curriculum conundrum must emerge from within each of them. That is part of the challenge of the twenty-first century to which we will return later. But first, what is conventionally meant by a 'subject'?

The word 'subject' in English has a number of meanings but the one relevant to this discussion is the second of six in the range offered by the Oxford English Dictionary, namely: 'a field of study (his best subject is geography)'. It is a curious coincidence that this renowned dictionary happens to select geography as an example of a subject because it is in fact a composite discipline. It may reasonably be said that all disciplines may be subjects but not all subjects may be disciplines. That is to say that some subjects seem to have clear parameters within the total stock of knowledge. Some, however, while having a clear identity, are in fact dependent of others for substantial proportions of their content. In the case of geography its essence or identity has been defined elsewhere by the writer as 'the spatial and locational analysis of the earth's surface phenomena' - the earth's surface being the layers from the outer edge of the atmosphere to the lower layers of the lithosphere (Brock, 1992, 2011, 2013). Diagrams in those sources show geography to comprise a number of sub-disciplines each dependent on other subjects or disciplines as follows:

\section{Geography: a Composite Discipline}

Physical Geography and Climatology: supported by geology, physics and cartography.

Biogeography: supported by biological sciences, geology and cartography.

Historical Geography: supported by history and cartography.

Economic Geography: supported by economics and cartography.

Political Geography: supported by political science and cartography.

Behavioural /Humanistic Geography: supported by psychology and cartography.

Cultural and Social Geography: supported by social anthropology, sociology and cartography.

Population Geography: supported by demography, statistics and cartography.

Applied Geography: supported by operational research, planning and cartography.

It is clear that cartography is fundamental to geography in that it is capable of giving precision to locational and spatial analysis and embodies the key component of scale, a vital yet neglected element of the study of education itself!

Although geography is perhaps the most obvious of the subjects in the conventional school curriculum to exhibit its interdisciplinary dependency, many of the same connections may be found 
in its close curricular relative, history. Indeed the two are fundamentally interdependent (Mackinder, 1913), for as Baker (2003) comments: 'I start as a geographer from the complementary premise that geography is not intelligible without history' (p. xi). There is of course political history, social history and economic history to say nothing of geological history (Zalasiewicz \& Williams, 2012). Then there are social psychology and physical and social anthropology. On the science side there are, for example, physical chemistry and bio-chemistry and so on and so on. All this reminds us of the Platonic wisdom that knowledge is one and indivisible; one of the legacies of the classical inheritance that has eluded school, and until recent years university, curricula.

So how is it that the conventional school curriculum has rendered knowledge divisible? As indicated above, part of the reason is that in the formative stages of the (European) curriculum it was devised fora male elite for very limited and selective purposes. Additional subjects in effect forced their way in as the interests of the elite changed and society progressed from feudal to industrial in terms of political economy. And there they still as are as 'tablets of stone' and bastions of a conventional wisdom beset by inertia.

Hunt (1969) refers to this stranglehold as 'The Tyranny of Subjects'. He contrasts the learning context of young pre-school children, that is to say the learning of skills through play, including for most some level of reading, with the transfer to formal schooling, where:

Reading has become a subject. You see it as 'work', something separate from your normal play activities. Soon other subjects are added. By the time you reach secondary school, you are confronted by a bewildering array of them. They take up most of your day and they tend to come in forty-minute slabs. You are expected to be equally interested in all of them. But not too interested because soon the bell will go: "Put your books away and get ready for the next lesson" (p.45).

Hunt concludes that 'the tyranny of subjects is still firmly established'. That was in 1969 but he would still be right today, despite intermittent effort and successes by some schools and teachers. For it is a prime purpose of formal education, especially in its compulsory stages, to act as a mechanism of social and political control in the interest of the state and its elite. So we need to examine the purposes of education.

\section{The Purposes of Education Today}

Formal and non-formal education have evolved over the centuries, indeed over more than one millennium, according to the purposes laid down for them by the powerful interactive forces of control: religious, political and economic. In the view of Richard Aldrich (2010) these forces have operated differentially, but also to a degree individually, to operate two purposive phases to date: a) education for salvation and b) education for economic development. In sequence, though overlapping, the prime force has been religious, then political, then economic. All three are still operational and influential, but to different degrees in each of the countries of the world. To these we may add 'territories' with their own education systems that are, at least to some degree, separate from nations as such. They may be, for the purposes of education, quasi-independent internal components of a nation such as the states of the USA or the Lande of Germany. Or they may be dependent territories of a metropolitan power.

The nature of education for salvation may be a dwindling purpose in the Western world, except in private schools run by religious bodies such as the parochial schools of the USA, but is a dominant force in some parts and countries of the world such as in Iran which is in effect a theocracy. Elsewhere in the Islamic world there are often madrassas especially for young children that impart a detailed knowledge of the Koran as a cornerstone of education for salvation.

In general, however, education for salvation as a prime purpose of formal schooling has long been overtaken by education for economic development as the predominant objective. In the 
place of religious rivalry, even of an inter denominational or inter-sect variety, we mostly now have national competition as a prime factor, even purpose, of formal education. Consequently we need to acknowledge and understand nationalism as a prime purpose of contemporary education.

\section{Nationalism and Education}

The emergence of nationalism in Europe necessarily affected the evolution of formal education and of the school curriculum that was to become a near global model. Before the emergence of the earlier nation-states of Europe the parameters of hegemony were already set as what Carr (1983) terms 'the medieval unity of Empire'. This hegemony had been achieved in association with, first, the Roman Catholic Church and then also the Protestant denominations emerging from the Lutheran Reformation. He sees a gradual but disparate impact of the agricultural and industrial revolutions, largely in the eighteenth and nineteenth centuries producing a 'democratisation of nationalism' that was secular. This led to the gradual liberalisation of school curricula, contested throughout by the resistance of classical traditionalists, and still within the firm grip of the governments of individual nation-states.

That grip was of course part of their security and survival, for as List in his 1904 publication The Nation al System of Political Economy, and quoted in Held (1983) indicates: 'The nation stands between the individual and entire humanity, and in all nations exists the impulse of self-protection' (p.174).

Hobsbawm (1992) describes how this imperative finds expression in one of the purposes of schooling:

Naturally states would use the increasingly powerful machinery for communicating with their inhabitants, above all the primary schools, to spread the image and heritage of the 'nation' and to inculcate attachment to it, and to attach all to country and flag, often 'inventing traditions' or even nations for this purpose (pp.91-2).

He goes on to explain that exercising this purpose of state schooling as a mechanism of social and political control requires mass literacy in a selected national language, which in turn makes the 'mass development of secondary education almost mandatory' (ibid, p.93). The reaching of this stage of compulsory schooling provision occurred differentially across the nation-states of Europe, North America and Australasia, with England and Wales coming last through the 1944 Education Act which was not fully implemented until about 1948. Such a kaleidoscope of European curricular legacies was inevitably distributed differentially across the colonial territories that several of the metropolitan powers had acquired. If one includes those powers themselves then by 1950 very few areas of the world were unaffected, notably parts of West Central Asia, plus Thailand, China and Japan (Taylor \& Flint, 2000).

Thailand has its own very distinctive story (Watson, 1980), while both China (Zhong,2013) and Japan (Suzuki, 2013) turned to western models of formal schooling and university provision in the late nineteenth century, leaving notably Afghanistan (Baiza, 2013) and Iran (Levers,2006) to follow by the mid-twentieth century.

The period since the 1939-45 world war has witnessed rapidly increasing modernisation worldwide, including the proliferation of new national systems as numerous colonies of the metropolitan powers gained political independence. As they did so they were faced with the same controlling imperative as had the elites and governments of the older systems, that of creating mass literacy through language policy. As Hobsbawm (1992) explains:

Both the direct administration of vast numbers of citizens by modern governments and the technical and economic development require this (a national language), for they make universal literacy desirable and the mass development of secondary education almost mandatory. It is the scale on which the state operates as well as its need for direct contacts 
with its citizens that create the problem. Thus mass education must, for practical reasons, be conducted in a vernacular, whereas education for a limited elite can be conducted in a language not understood or spoken by the body of the population, or, in the case of classical languages like Latin, Classical Persian or classical written Chinese, by anyone at all ( pp. 93-4).

The oldest post-classical polities, England, France and Russia, together with the later emergent USA and Germany, have been compared by Greenwood (1992) in her massive work: Nationalism: Five Roads to Modernity. As these nations moved through technical innovation and industrialisation towards modernity different levels of literacy occurred as between diversifying social structures. This could and did lead to conflicts over knowledge in view of its potential power.

In England the bible became, in effect by default, a massive resource for popular literacy, being 'not simply a book they all read, but the only book they read' (Greenwood, 1992, p.54). The encouragement of creative culture in the sixteenth century coincided with the establishment of the Church of England as the creature of the monarchy. As such it sought to restrict and even destroy a flowering empirical trend encouraged by the non-conformist dissenting academies which were challenging the moribund monopoly of higher education in England that comprised only two universities, Oxford and Cambridge. When Joseph Priestley, an ordained non-conformist priest and scientist worked towards the discovery of Oxygen at the banned Warrington Academy, the institution was destroyed and his life threatened. King George III even intervened stating that Priestley should 'now feel the wickedness of democracy that he was propagating' ( $O$ 'Brien, 1989, p.133). But the momentum of reform was under way and in 1828 a secular university was founded by the Utilitarian movement led by Jeremy Bentham. This was University College, London, termed by Lawson and Silver (1973) 'the middle class university' ( p.258), but the Church of England responded immediately with two new universities of its own, King's College, London in 1831 and Durham University in 1832. The battle between the social and largely Anglican political elite of England and the largely secular professions, including science and technology, is ongoing in England to this very day and evident in the constraints it places on, for example, the popular acceptance of climate change, an issue of vital concern for humankind in the twenty-first century.

That situation contrasted sharply with France where the nobility, not the bourgeoisie, was the liberally educated class before the revolution. This survived the social and political upheaval, so that subsequent political and social elites have relied on the 'Ecoles Superieurs' for their own professional and technical training. To some extent likewise in Russia where first Peter the Great ( ruled from 1682-1725), and then Catherine the Great (ruled from 1962-1796), encouraged the development of both technical and higher education to the extent that the popularity of Moscow University, founded in 1755, led to what Greenwood has described as the 'enoblement' of 'aristocratization' of higher education (1992, p.214).

Unlike the well-established and relatively stable territories of England, France and Russia the 'German Realm' of pre-industrial Europe comprised hundreds of small princely states. There was of course an intellectual elite but the noble and ruling elites sponsored universities in order to train their own clergy, technicians and civil servants as a counter to the educational influence of the Roman Catholic Church. In practice this meant higher education and thereby the strengthening of the middle classes. This may at least be a contributory cause of the greater recognition of technical and vocational learning in Germany than in most other Western European states, and a factor in the nature of the structure and curricula of the contemporary school system.

To some degree this concurs with the experience of the other emergent power of the eighteenth and nineteenth centuries, the USA, born of the American colonies of Britain that were its precursor for over 150 years. Here, the generally high literacy level of the formative immigrant population, the lack of a noble political elite and the practical problems of colonising a new terrain, albeit with an indigenous population, placed a high priority on practicality. Basic schooling was imperative within each small settlement (Daniels, 1979) and democratically operated. Open opportunity and competition led to a proliferation of colleges alongside a few more colonially established elite institutions. In contrast to the more intellectual traditions of learning in the 'old country' Greenwood 
states that, in what became the USA, the 'attitude was uncongenial to imaginative and speculative writing but it fostered empirical study' (1992, p.464).

So, with respect to the formation of school curricula during two centuries of modernisation, it is clear that there are both convergent and divergent forces at work as between the nations that formed what has become, in effect, the global curriculum. Their purposes may be divergent in detail, but with the modernisation of the twentieth century came increasing competition.

\section{Modernisation, Culture, and International Competition}

There has always been competition between states, from the wars of the early city states of Classical Greece to the Israel/Palestinian conflict of today. Until the mid-nineteenth century these were largely about territory and physical resources. Current tensions in Ukraine relate in part to such factors but have also to do with language, culture and national identity. Education is culturally embedded though, in terms of formal modes, largely politically controlled and delivered and has become an increasingly significant factor in terms of international competition.

Education became a key issue from the mid- nineteenth century. In 1851 Britain organised the 'Great Exhibition' which was 'Britain's demonstration of her manufacturing supremacy, challenges to which only began to cause anxiety from the late sixties' (Lawson \& Sliver, 1973, p.268). By that time it had become evident that France, Germany and the USA were in process of overtaking. The American Civil War of 1861-1865 temporarily damaged economic progress there but it also prompted innovation. Most significantly it confirmed the USA as a single nation with a single currency, the \$US. Almost contemporary, the Franco-Prussian War of 1870-1871 was a step on the way to Prussian supremacy and the formation of a unified Germany.

All of these events had important educational implications especially to increase the pace and purpose of schooling. This was the beginning of Aldrich's phase of 'education for progress, meaning national economic development. The younger, more instrumentally-oriented curricula of Germany and the USA were more tuned in to this objective than those of the older three firmly established states, England, France and Russia. England in particular did not institute the regulation for universal primary education until education until 1870, and did not achieve it until the turn of the century. The logical follow on of universal secondary education was strangled at birth by the Cockerton judgement of 1901, a decision reminiscent of that affecting Leeds Grammar School a century earlier! Britain was still the wealthiest nation and the greatest global power at the time, but in so far as education had anything to do with it, it was the leadership ethic of the private boarding schools for boys, known perversely to this day as 'public schools'. Massive wealth had accrued from colonial exploitation, but when the country was bankrupted by the 1914-1918 war, universal secondary education was still a quarter of a century away!

As already mentioned China and Japan embarked on a western model of schooling in the late nineteenth century in the interests of modernisation. Deep cultural roots prevented Japanese colonial attempts to recast curricula in areas they colonised in China and Korea, while such roots also prevented attempts by the powers occupying Germany to effect curricular reforms in their own image. Throughout the second half of the twentieth century, and despite the creation of international and multinational bodies such as the United Nations Agencies, the World Bank Group and the European Union, the purpose of compulsory education has remained nationalistic and competitive with the twin objectives of serving economic growth and political control.

Such further and intensifying competition contributes to the near universal nature of school curricula in the interests of comparability. Attempts to create league tables of national success in schooling are made feasible by this global curriculum, attempts such as TIMMS and PISA. The latter claims to be predictive of future national economic growth on the evidence of tests of young teenagers in a limited range of subjects. It is as if other aspects of the educational experiences of people such as non-formal and formal further and higher education, to say nothing of the massive influence on every individual of informal education, have no influence at all! The emergence of International University 
Rankings has similarly fixated politicians in all countries, further concentrating their attention on research ratings and related funding rewards. Irrespective of the deep deficiencies in the methodology of these comparisons, are they helping or hindering the purpose of education for survival that must be the objective in the twenty-first century? The 'good money', as the saying goes, must be on the latter.

\section{The Massive Challenge of Twenty-First Century Survival}

For at least three decades perceptive scientists have become aware that the human species is capable of destroying its habitat, planet Earth, and in doing so, itself as well. This not in dispute, except of course by politicians around the world, whose main preoccupations are with nationalism and their own careers.

At the core of the concern of scientists about the twenty-first century is The Gaia Principle, set out by James Lovelock and Lynn Margulis in the 1970s. Gaia sees the Earth, from the outer atmosphere to, and including, the lithosphere, as a self-regulating complex of organic and inorganic forms that maintains the balance of all forms of life to survive. Successive Gaia Conferences in 1985, 1988,2000 and 2006 increasingly illuminated both the critical issues that will arise in the $21^{\text {st }}$ century and how they might be addressed. The extraordinary way in which planet Earth has so far managed to sustain itself and its life forms has become known as The Goldilocks Effect. This means, in simple terms being 'not too hot and not too cold', as in the children's story from which it takes its name. The principles of Gaia and Goldilocks have found applications in many disciplines across the spectrum of human knowledge. They have also given rise to immense concern. So much so that James Lovelock published his book The Revenge of Gaia: Why the Earth is Fighting Back - And How We Can Still Save Humanity in 2006. In the same year James Martin emphasised the significance of the $21^{\text {st }}$ century in his book The Meaning of the $21^{\text {st }}$ Century: A Vital Blueprint for Ensuring Our Future.

So it is clear that the challenges faced by the current near universal 'global curriculum', as it has developed in association with nation-states have already been overtaken by new international challenges that have so far been largely ignored by both politicians and the majority of human society. Significantly they have not been ignored by millions of so-called lesser species of life that continue to operate within Gaia principles!

What are these urgent challenges and their implications, and what can education do to help meet them? Education is beginning to be recognised, and being identified as a kind of panacea to bring the human species to its senses before it is too late, but what can education do to meet these challenges? In his book James Martin (2006) lays out seventeen (17) 'Challenges of the $21^{\text {st }}$ Century' (pp. 227-236) and indicates what needs to be done to meet them. To paraphrase:

1. The Earth: stop actions leading to climate change, polluting rivers and lakes, breaching the ozone layer, wasting fresh water. On the plus side we have massive new super-computer models and could learn more from science and good teaching.

2. Poverty: all nations need to reach a 'decent literacy rate' and adequate levels of employment.

3. Population: overpopulation needs to be curbed by raising the educational levels of women. 'The goal of improving lifestyles equates to the goal of lowering population'

4. Lifestyles: $20^{\text {th }}$ century lifestyles cannot be sustained, but technology has the potential to support new comfortable lifestyles in keeping with sustaining the environment.

5. War: 'The existence of weapons capable of ending civilisation makes this a very different century from any before'. Weapons control and eradication is essential for survival.

6. Globalism: This is already here but must be adjusted to allow unique cultures to survive because localism is vital to sustainability. The global /local link is fundamental.

7. The Biosphere: 'Global management of the biosphere is essential': must make a computerinventoried knowledge of all species soon.

8. Terrorism: All grade uranium and plutonium must be locked. The reasons why people become terrorists must be eradicated, including the mutual respect of all religions for each other to prevent their perversion. 
9. Creativity: Current and future technology can support massively increased creativity in the interests of innovative interventions to progress sustainability, human and environmental.

10. Disease: Increasing potential for pandemics (including terrorist generated) must be resisted by appropriate defences.

11. Human Potential: Most people today 'fall outrageously short of their potential' Digital media need to be devised to develop the capability latent in everybody in all human societies.

12. The Singularity: This is the chain reaction of computer intelligence. It needs to be controlled to enable appropriate education of young people to cope with self-evolving technologies that will become 'infinite in all directions'

13. Existential Risk: These are risks that could lead to the termination of the human species. Martin says that 'the most dangerous time will probably be just ahead of us, when we argue about whether we should control science'. We must, because at present the best estimates give us only a 50/50 chance.

14. Transhumanism: Nanotechnology connected to the brain will 'change human capability in extraordinary ways', but will create an increasingly wider gap between rich and poor. It will enable increasingly advanced civilizations in all aspects of life.

15. Advanced Civilization: 'Any civilization of the future will permeate cyberspace' and decisions made in the $21^{\text {st }}$ century relating to the management of planet Earth. Martin quotes Lord Rees as follows: 'the prime concern of the $21^{\text {st }}$ century is that we should survive it'

16. Gaia: 'Gaia does its own thing and we must learn to live within its constraints'. If not, Earth will become a 'roasted planet' with few surviving only at the poles.

17. The Skill-Wisdom Gap: 'Science and technology are accelerating furiously but wisdom is not'. Wisdom depends on synthesis but is challenged by the capacity of science to create wealth quickly. We need more inter-disciplinarity. Corporate greed and corruption could destroy us and the planet. 'We need to set out very consciously to foster and nurture the wisdom the $21^{\text {st }}$ century will require'

\section{Implications for Education and Curricula}

James Martin concludes his concern about the crucial role of wisdom with regard to homo sapiens surviving the $21^{\text {st }}$ century by stating that: 'This should be a task for our greatest universities' (2006, p.236). He also comments that the potential for Advanced Civilizations could be as big an influence on human history as the Renaissance. We need to remember that it was the curricula of the renaissance universities of Western Europe that controlled the curricula of schooling as the European nation-states developed. Now, in 2014 and well into $21^{\text {st }}$ century does it look as if the universities of today will help in the way that James Martin regards as essential? Not according to Nicholas Maxwell of University College, London who states in a letter to The Guardian newspaper of October, 2013:

Of course universities should invest in the future. The problem is they don't. Climate change, population growth, mass extinctions and other global problems mean that we are heading towards disaster. If we are to make progress towards as good a world as possible - or at least avoid the worst of disasters - we need to learn how to do it. That in turn requires that our institutions of learning are rationally designed and devoted to the task...The key crisis of our times is the failure of our universities to help us learn how to make progress towards a better world.

There has, as Martin acknowledged, been some recognition of the imperative of greater inter - disciplinary enquiry, teaching and research, but the cult of specialism still dominates both funding and individual promotion. So we must here be more concerned with school, especially secondary school, curricula. This has become locked into a conventional individual subject model on the basis of which universities select their undergraduate intake. The fact that the majority of the world's 
secondary school leavers do not proceed to post-secondary or higher education seems to have been overlooked or, even worse, disregarded. Most politicians in most countries experienced elite secondary schooling and subsequent university education. They have little or no experience of the realities of the lives, including the schooling, of most people in their respective countries. As King and Crewe (2013) point out in respect of incredible policy disasters, in their word 'blunders', by UK governments over the past $30+$ years, that most ministers and top civil servants had no ideas as to the realities of most people's lives and circumstances in the United Kingdom. This is likely true of most governments and administrations. King and Crewe also show that failure to understand technology has been behind many of the policy disasters in the UK: 'One of the most remarkable features of successive governments' ventures into the field of Information Technology (IT) is that they have gone on and on making the same mistakes. They never seem to learn' (2013, p.184). And as we have seen from Martin (2006): 'science and technology are accelerating furiously' (p.235), and that there is an urgent need to understand and control them in the interests of surviving the $21^{\text {st }}$ century.

It is popularly imagined that technology and education will save us! But clearly we need to develop forms of education that will save us from unregulated technology, which also includes regulation in the wrong way. In any case Emmot has clearly shown in his 2013 book 10 Billion that 'on today's evidence technologizing our way out of this does not seem likely' (p.167) 'so...the only solution left to us is to change our behaviour, radically and globally at every level' (p.168). Such a change of behaviour would require massive educational change at all levels for both adults (nonformal and informal education) and for those of compulsory schooling age. There would also need to be radical reform of funding, style and above all, curricula.

\section{What Kind of Curricula to Meet the Challenges?}

For the purposes of this section of the paper it must be assumed that governments revise their views as to the prime purpose of education, and very urgently. Otherwise it will be too late. Sadly this assumption must for now be theoretical as governments everywhere, not to mention their populations, show no signs of appreciating the problem or its urgency. As Martin (2006) has indicated 'Because humankind underestimated the fragility and complexity of nature, it also had various grand-scale misconceptions about its own supremacy' (p.25). Emmott (2013) concludes his perceptive contribution to the debate as follows:

As I said at the beginning, we can rightly call the situation we're in an unprecedented emergency...We urgently need to do - and I mean actually do - something radical to avert a global catastrophe. But don't think we will (pp.195-6).

However, what hope there may be lies in the younger generations of today if they are provided with a rapidly radically reformed educational experience. Young people now at secondary school are, in general, a lost generation, as most will leave formal education before any radical curriculum change could be effected. So at best we are talking about today's primary school pupils, and then only the youngest because of the time it would take governments to effect radical reforms, if they ever do! But we must try to convince them. A radical reform is required not a 'tweaking' here and there because the existing curricular structure has slowly emerged to support numerous nationalisms. So a logical place to begin is to relate Martin's seventeen (17) $21^{\text {st }}$ Century Challenges to a new curricular scheme. Some can be conflated but none can be ignored, nor can the fundamental requirement of sufficient levels of literacy and numeracy.

\section{Curriculum Cluster A: Communication}

Literacy, command of language, and numeracy, command of numbers and symbols should be seen as one, the command of communication. This must, by definition, include information 
communications technology (ICT) in view of the aforementioned and absolute need for human beings to understand 'the Singularity. Without such understanding, homo sapiens will lose control of computer technology and everything will be destroyed. This would include transhumanism and advanced civilisations. Mathematics (numbers and symbols and logic) is currently seen as belonging only with science which has been a huge mistake even though it is essential there too.

\section{Curriculum Cluster B: Gaia and the Biosphere}

This needs to be understood and fully enabled to survive. It would require an integrated, though basic, understanding of the natural sciences: biology, chemistry, geology and physics. Within this cluster geology, together with physical geography, needs to come to the fore together with atmospheric physics. This, so that the whole range of the earth's 'layers' from the outer edge of the atmosphere to the inner edge of the lithosphere can be comprehended as an integrated whole. Geology is usually absent from school curricula at this level which means that the crucial interplay between rocks and the atmosphere that creates soil is neglected. The fundamental but simple process of photosynthesis, on which all life on land depends, also needs to be a central theme together with the tropical rain forests and the oceans. Accepting and understanding climate change, as outlined in The Goldilocks Planet: the Four Billion Year Story of Earth's Climate (Zalasiewicz \& Williams, 2012) at this level of schooling is essential and perfectly feasible, likewise the ecological balance between humankind and nature. As Sir Ken Robinson indicated in his celebrated TED lecture of 2006 'Do Schools Kill Creativity, if all insects were exterminated all life on earth would die, but if all humans were exterminated all other forms of life would flourish. Crucial issues such as the massive significance of bacteria must be included in the interests of health and survival.

\section{Cluster C: Poverty and Population}

There are far too many people on earth already and the overall rate of increase is increasing. Despite the fact that in the most affluent countries the number of births is now insufficient to renew the population at is current number, the overall global increase is a threat to us all. To understand this means engaging at a simple level with demography, economics and the other social sciences. Basic facts and concepts from all of these: sociology, anthropology, economics and politics, together with aspects of human geography, history and psychology, can be used to illustrate key issues of poverty and population. This gives a chance to being prepared to meet the $21^{\text {st }}$ century challenges of transhumanism, advanced civilisations and the lifestyles that will enable them. There will still be rich and poor relative to each other but the gap between them would become manageable, without which conflicts will likely escalate in number and severity. A key issue within this is population mobility, already a key political challenge to nation states.

\section{Cluster D: War and Terrorism}

Violent human conflict is an obvious deterrent to the survival of both humankind and the environment. Homo sapiens is by far the most destructive species ever to exist and almost unique in its violence towards itself. This has traditionally been driven by tribalism, nationalism, religion and other issues of identity. Weapons of mass destruction make a global war less likely than before, but smaller local and regional conflicts are innumerable and increasing. To most people, including the young, war and terrorism appear to be almost normal features of modern society. Films and television shows involving violence, especially murder, are widely popular as are novels of the same genre. Some recent governments have been little better, invoking violent intervention in the territory of others without necessarily being attacked themselves. Appropriate content in the study of politics, religion and identity in relation to war and terrorism should be part of this curriculum, which should also encourage mass participation in democratic politics in the interest of avoiding elective dictatorships which are almost the norm today. 


\section{Conclusion: From Curriculum to Syllabus}

There will of course be predictable criticisms from traditionalists who will say that students in the four or five years of secondary school need to learn the basics of individual subjects before relating them to others. They will also say that students at this stage should cease to study some subjects in the interests of preparing for specialisation at the post-compulsory stage. But we cannot afford that luxury even if it were desirable. The key concepts in the clusters outlined above are capable of relatively simple explanation. This especially so if combined with non-formal and informal learning that will be going on outside the school anyway in the media and in the community. Such a conflation of the three forms of education is illustrated in Education as a Global Concern (Brock, 2011, p.145). This localisation of learning, in harness with the global, is exactly what Martin (2006) is advocating when he stated '...globalism should be designed to allow unique cultures to thrive and be protected. The right balance between what is global and what is local needs to be achieved' (p.25). In Brock (2010, p.145) the universities are shown as participating fully in reaching this objective, thus also meeting Maxwell's criticism of them above.

We have to consider how the secondary school curriculum clusters suggested above can be operated in the form of a syllabus.

The preceding primary years would need to be strongly focussed on communication in the forms of literacy, numeracy and ICT, the last-named increasingly becoming the medium of learning and creativity. This can be achieved by relating the three facets of communication to practical issues of simple human and environmental ecology, geological history (dinosaurs and other extinct fossils), social history and creative and performing arts. In the compulsory secondary four to five years the syllabus could be split more or less evenly between integrated studies based on the curriculum clusters above and individual subject studies. Obviously the two approaches would need to be coordinated by careful planning and timetabling. Computers will be increasingly able to handle that if programmed appropriately, and not so far into the future, as the Singularity approaches, they will be able to generate suitable syllabuses on their own.

For any of this to happen, nationalism and corporatism that have been the drivers of the conventional global syllabus in the interest of their purposes of education - political and social control and blind economic growth - must not be allowed to hold the power they have now: power that is fossilising the curriculum. If we do not want to become fossils ourselves any time soon we must make - and rapidly - the kind of radical curricular changes advocated above.

Education in itself cannot save us but it might be able to save us from the excesses of computer technology because 'the capability for handling the Singularity will be distributed globally, particularly among appropriately educated young people' (Martin, 2006, p.231). This article has attempted to point towards what would be appropriate in curricular terms to serve that new purpose of education in contrast to that nineteenth and twentieth century purpose of nationalism and competitive economic growth that needs to die, and soon.

\section{References}

Aldrich, R. (2010). Education for Survival: an historical perspective History of Education 39(1), pp.1-14. Baker, A. R. H. (1983) Geography and History: Bridging the Divide. Cambridge: Cambridge University Press.

Baiza, Y. (2013). Afghanistan: Religion, State and Education. In Ahmed, Mah-E-Rukh (Ed) Education in West Central Asia. London: Bloomsbury, pp.21-38.

Belth, M. (1965). Education as a Discipline. Boston: Allyn and Bacon Inc.

Brock, C. (1992) The Case for a Geography of Education. Unpublished PhD thesis. University of Hull.

Brock, C. (2007). Historical and Societal Roots of Accreditation of Higher Education for Quality Assurance. In: GUNI (Ed) Higher Education in the World 2007. Accreditation for Quality Assurance: What is at Stake? Basingstoke: Palgrave Macmillan, pp.24-36. 
Brock, C. (2010). Spatial Dimensions of Christianity and Education in Western European History, with Legacies for the Present. Comparative Education 46(3), pp.289-306.

Brock, C. (2011). Education as a Global Concern. London and New York: Continuum Books.

Brock, C. (2013).The Geography of Education and Comparative Education. Comparative Education 49(3), pp.275-289.

Brock, C. \& Cammish, N. K. (1997). Factors Affecting Female Participation in Education in Seven Developing Countries. London: DfID.

Carnoy, M. (1974). Education as Cultural Imperialism. New York: David McKay Co.

Carr, E. (1983). States and Nationalism. The Nation in European History. In D. Held (Ed). States and Societies. Blackwell: Oxford, pp.181-194.

Daniels, B. C. (1979). The Connecticut Town: growth and development 1635-1790. Middletown CT: Wesleyan University Press.

Dickens, A.G. (1974). The German Nation and Martin Luther. London: Edward Arnold.

Dodgshon, R.A. (1987). The European Past: Social Evolution and the Spatial Order. Basingstoke: Macmillan.

Elliott, P. \& Daniels, S. (2010). No Study so Agreeable to the Youthful Mind: geographical education in the Georgian grammar school. History of Education 39(1), p.1.

Emmott, S. (2013) 10 Billion. London: Penguin.

Greenwood, L. (1992). Nationalism: Five Roads to Modernity. Cambridge Mass: Harvard University Press.

Held, D. (1983) States and Societies. Oxford: Blackwell/Open University Press.

Hobsbawm, E. J. (1992). Nations and Nationalism since 1780: programme, myth, reality. Cambridge: Cambridge University Press.

Hopper, C. (1968). A Typology for the Classification of Educational Systems. Sociology 2, pp.29-46.

Hunt, A. (1969). The Tyranny of Subjects. In D. Rubenstein \& C. Stoneman (Eds). Education for Democracy. Harmondsworth: Penguin.

King, A \& Crewe, I. (2013). The Blunders of our Governments, London, Oneworld Publications.

Lawson, J. \& Silver, H. (1973). A Social History of Education in England. London: Methuen.

Levers, L. Z. (2006). Ideology and Change in Iranian Education. In R. Griffin (Ed) Education in the Muslim World: different perspectives. Didcot: Symposium Books, pp.149-190.

Lovelock, J. (2006) The Revenge of Gaia: why the earth is fighting back - and how we can still save humanity. London: Penguin.

Mackinder, H.K. (1913). The Teaching of Geography and History as a Combined Subject. The Geographical Teacher, 7, p.35.

Mallinson, V. (1980). The Western European Idea of Education. Oxford: Elsevier.

Martin, J. (2006). The Meaning of the $21^{\text {st }}$ Century: a vital blueprint for ensuring our future. London: Transworld / Eden Project Books.

O’Brien, P. (1989). Warrington Academy 1757-86: its predecessors and successors. Wigan: Owl Books.

Robinson, K. (2006) Do Schools Kill Creativity? Available at: http://www.ted.com/talks/ken_robinson_ says_schools_kill_creativity\# [Accessed 14 February 2014].

Suzuki, S. (2013). Japan: cultural roots versus systemic provision. In P.J. Hsieh (Ed). Education in East Asia. London: Bloomsbury, pp.103-126.

Taylor, P.J. \& Flint, C. (2000). Political Geography. World Economy, Nation-State and Locality. Harlow: Prentice Hall.

Watson, J.K. (1980). Educational Development in Thailand. Hong Kong: Heinemann Asia.

Zalasiewicz, J. \& Williams, M. (2012). The Goldilocks Planet: the four billion year story of earth's climate. Oxford: Oxford University Press.

Zhong, Z. (2013). China: an overview. In P.J. Hsieh (Ed). Education in East Asia. London: Bloomsbury, pp.1-28. 